\title{
A GESTÃo EDUCACIONAL NOS PLANOS DE EDUCAÇÃO: DO NACIONAL AO MUNICIPAL
}

\section{LA GESTIÓN EDUCACIONAL EN LOS PLANES DE EDUCACIÓN: DEL NACIONAL AL MUNICIPAL}

\author{
EDUCATIONAL MANAGEMENT IN EDUCATION PLANS: FROM NATIONAL TO \\ MUNICIPAL
}

\author{
Andréia Vicência Vitor ALVES ${ }^{1}$ \\ Andrêssa Gomes de Rezende ALVES ${ }^{2}$ \\ Elis Regina dos Santos VIEGAS ${ }^{3}$
}

RESUMO: Este trabalho objetiva analisar a gestão educacional nos Planos de Educação, com especial atenção aos Planos Nacionais de Educação (2001-2011 a 2014-2024) que orientam a elaboração e adequação dos Planos Estaduais e Municipais de Educação. Ao considerar que o PNE (2014-2024) exigiu o alinhamento entre os Planos de Educação no âmbito estadual, distrital e municipal, trabalhou-se com pesquisa bibliográfica e documental. Constatou-se que a elaboração ou adequação dos Planos Estaduais e Municipais de Educação não expressou alterações consideráveis em relação as suas especificidades e a maioria deles apresenta uma reescrita da meta 19 do PNE (2014-2014). A situação em tela revelou que mesmo sendo prevista a construção dos PEEs e PMEs pelos estados e municípios, considerando as suas singularidades locais, eles não a realizaram no que se refere à gestão democrática. $\mathrm{Na}$ construção dos planos educacionais ocorreu ainda uma disputa pela hegemonia do pensamento educacional, o que implica diretamente na elaboração da concepção de gestão educacional.

PALAVRAS-CHAVE: Política educacional. PNE. PEE. PME. Meta 19.

RESUMEN: Este trabajo tiene por objeto analizar la gestión educacional en los Planes de Educación, con especial atención a los Planes Nacionales de Educación (2001-2011 a 20142024) que orientan la colaboración y adecuación de los Planes Estaduales y Municipales de Educación. Al considerar que el PNE (2014-2024) exigió la alineación entre los Planes de Educación en el ámbito estadual, distrital y municipal, se trabajó con investigación bibliográfica y documental. Se constató que la elaboración o adecuación de los Planes Estaduales y Municipales de Educación no expresó alteraciones considerables con relación a sus especificidades y la mayoría de ellos presenta una reescrita de la meta 19 del PNE (20142014). La situación en cuestión reveló que, aunque prevista la construcción de los PEEs y

${ }^{1}$ Universidade Federal da Grande Dourados (UFGD), Dourados - MS - Brasil. Docente do Programa de Pósgraduação em Educação. Doutora em Educação. ORCID: https://orcid.org/0000-0002-5179-4053. E-mail: andreiaalves@ufgd.edu.br

${ }^{2}$ Universidade Estadual de Mato Grosso do Sul (UEMS), Mundo Novo - MS - Brasil. Docente da Unidade Universitária de Mundo Novo. Doutora em Educação. ORCID: https://orcid.org/0000-0002-2344-454X. E-mail: andressa_rezend@hotmail.com

${ }^{3}$ Secretaria Municipal de Educação de Dourados (SEMED), Dourados - MS - Brasil. Técnica Pedagógica do Núcleo de Educação Infantil. Doutora em Educação. ORCID: https://orcid.org/0000-0002-9557-3471. E-mail: elisreginaviegas@gmail.com 
PMEs por los estados y municipios, considerando sus singularidades locales, ellos no la realizaron en lo que respecta a la gestión democrática. En la construcción de los planes educacionales ocurrió también una disputa por la hegemonía del pensamiento educacional, lo que implica directamente en la elaboración de la concepción de gestión educacional.

PALABRAS CLAVE: Política educacional. PNE. PEE. PME. Meta 19.

ABSTRACT: This work aims to analyze the educational management in the Education Plans, with special attention to the National Education Plans (2001-2011 to 2014-2024) that guide the elaboration and adaptation of the State and Municipal Education Plans. When considering that the PNE (2014-2024) required the alignment between the Education Plans at the state, district and municipal levels, bibliographic and documentary research was done. It was found that the elaboration or adequacy of the State and Municipal Education Plans did not express considerable changes in relation to their specificities and most of them present a rewrite of the PNE goal 19 (2014-2014). The situation at hand revealed that even though the construction of PEEs and SMEs by the states and municipalities was foreseen, considering their local singularities, they did not carry it out with regard to democratic management. In the construction of educational plans, there was still a dispute for the hegemony of educational thought, which directly implies the elaboration of the conception of educational management.

KEYWORDS: Educational policy. PNE. PEE. PME. Goal 19.

\section{Introdução}

No cenário atual, as interlocuções que envolvem gestão educacional e planos de educação no Brasil têm ganhado força em termos de políticas governamentais por meio das orientações advindas do Plano Nacional de Educação (PNE 2014-2014), aprovado pela Lei no 13.005 de 2014. Este documento tem sido apresentado como norte diretivo para mudanças no panorama da gestão educacional no âmbito federativo.

Como forma de compreendermos tal conjuntura, bem como mapear a produção da literatura sobre a temática, recorremos a um breve levantamento do conhecimento junto ao Catálogo de Teses e Dissertações Capes ${ }^{4}$, com a finalidade de sistematizar a produção do objeto em tela, assim como fundamentar as análises empreendidas ao longo deste trabalho. Para isso, selecionamos como descritores: "gestão educacional", "Plano Nacional de Educação (PNE)", "Plano Estadual de Educação (PEE)" e "Plano Municipal de Educação (PME)".

A opção pelos descritores supracitados se justifica em razão de compreendermos que a ideia de um PNE surge da intenção legal, prevista no art. 214 da Constituição Federal Brasileira

${ }^{4}$ Disponível em: https://catalogodeteses.capes.gov.br/catalogo-teses/\#!/. Acesso em: set. 2019. 
(CF) de 1988, de articular e desenvolver o ensino em seus diversos níveis e, ainda, integrar as ações do poder público.

Tal intenção situa-se na percepção, indicada por Lück (2011, p. 25), de que "a gestão educacional corresponde à área de atuação responsável por estabelecer o direcionamento e a mobilização capazes de sustentar e dinamizar o modo de ser e de fazer dos sistemas de ensino". Assim, foi possível identificar especificamente as relações e as análises empreendidas pelos pesquisadores, como forma de compreendermos as opções e o delineamento das investigações desenvolvidas.

Destarte, identificamos um total de 51 trabalhos (43 dissertações e 8 teses), com recorte temporal de defesa das pesquisas de 1997 a 2018. A região com maior número (próximo de $33,3 \%$ ) de trabalhos é a Sudeste; seguida da região Sul (por volta de 19,6\%); Nordeste (17,6\%) e outras regiões, Centro-Oeste e Norte, ambas com aproximadamente 15,7\% e 13,8\%, respectivamente.

Dentro destas, os estados com maior expressão em termos de registros de defesas é o Mato Grosso do Sul (MS), com 9 trabalhos (8 dissertações e 1 tese), contrariando a tendência geral registrada por região; embora a tendência seja retomada na sequência, conforme sinalizado, dois estados computaram o segundo maior número de pesquisas, Rio de Janeiro (RJ) e São Paulo (SP), com 8 trabalhos cada (ambos 7 dissertações e 1 tese); depois tem-se o Rio Grande do Sul (RS), com 6 defesas (4 dissertações e 2 teses), e também Pernambuco (PE) e Tocantins (TO), com 4 trabalhos cada (PE 3 dissertações e 1 tese e TO 4 de mestrado). Neste cenário, ainda há 5 estados e o Distrito Federal (DF) com 2 trabalhos cada: Paraná (PR), Santa Catarina (SC), Bahia (BA), Ceará (CE) e o Pará (PA). Somente o PR e BA tiveram 1 defesa de doutoramento, o restante apresenta apenas dissertações. Por fim, 4 estados com 1 trabalho cada: Espírito Santo (ES), Goiás (GO), Alagoas (AL) e Acre (AC), todos de mestrado.

No que se refere às Instituições de Ensino Superior (IES), não identificamos um quantitativo expressivo de pesquisas por instituição; o que pudemos observar foi uma variação de 1 a 4 defesas, com destaque para as instituições: Universidade Federal do Tocantins (UFTO) e Universidade Estadual Paulista Júlio de Mesquita Filho (UNESP), ambas com 4 pesquisas, todas dissertações de mestrado. Há, ainda, a Universidade Federal de Pernambuco (PE), com 3 trabalhos (2 dissertações e 1 tese).

No que diz respeito ao conteúdo das pesquisas - direcionados à gestão educacional em relação ao PNE e PEE -, podemos inferir que a maioria $(64,7 \%)$ tomaram como objeto "PNE" (2001-2011 e/ou 2014-2024) ou PPEs dentro de suas respectivas unidades federativas, aparecendo a discussão ou análise da "gestão educacional” em segundo plano. 
Já os trabalhos (35,3\%), que se relacionam à gestão educacional com $\mathrm{PME}^{5}$ ou do $\mathrm{PNE}$ ao PME, diferem em sua maioria da abordagem adotada dos anteriores (com objeto central os PNE ou PEE). Tais desenhos investigativos apontaram preocupações em relação à viabilidade ou efetivação dos PMEs de um modo geral, ao considerar o cenário complexo das municipalidades brasileiras: desafios do PME na gestão e no financiamento da educação local; identificação e análise dos obstáculos existentes na implantação e funcionamento de políticas de formação e valorização docente; características políticas e negociações que ocorreram no processo de elaboração e de implementação do PME; desafios que o PNE estabelece aos municípios brasileiros; perspectivas e contradições dos PNE e seus desdobramentos nos PMEs para o processo de institucionalização efetiva do Sistema Nacional de Educação (SNE) e para a definição das políticas e gestão da educação.

Diante disso, o levantamento desenvolvido revela a necessidade de apreender o processo gestão educacional e seus desdobramentos nos Planos de Educação tanto como meta quanto política de efetivação dos Planos. De tal modo, este trabalho se justifica pela necessidade de ampliar o campo de estudo, haja vista.

Desta feita, o objetivo do presente artigo é analisar a gestão educacional nos Planos de Educação, com especial atenção aos Planos Nacionais de Educação (2001-2011 e 2014-2024) que orientam a elaboração e adequação dos Planos Estaduais e Municipais de Educação, levando em consideração que o PNE (2014-2024) exigiu o alinhamento entre os Planos de Educação no âmbito dos estadual, distrital e municipal. Isso por meio de levantamento bibliográfico e de pesquisa documental.

Num primeiro momento o artigo abarca os Planos de Educação, em especial, o PNE (2001-2011) e o PNE (2014-2024), além de apresentar aspectos da construção do PEE e do PME. A seguir aborda a gestão educacional, e, assim, a gestão democrática da educação, explanando como ela vem sendo configurada nos planos de educação.

\section{Aspectos sobre a construção dos planos de educação}

É propósito desta seção retomar os aspectos históricos concernentes ao PNE, analisando, em especial, os Planos aprovados pós CF de 1988, a saber: o PNE (2001-2011) aprovado pela Lei no 10.172, de 2001 e o PNE (2014-2024), levando em consideração que o PNE (2001-2011)

\footnotetext{
${ }^{5}$ Municípios identificados: da região dos estados de SP (Santo André e Rio Claro), RJ (Rio Bonito e Mesquita), MS (Naviraí), CE (Fortaleza), PE (Recife), PA (Altamira), ES (Vila Velha e Serra), BA (Serrinha), AC (Rio Branco), RS (Esteio) e TO (vários municípios).
} 
foi o primeiro consolidado no país, além de apresentar aspectos da construção do PEE e do PME.

É importante destacar que, com a promulgação da CF de 1988, foram estabelecidos os direitos civis, políticos e sociais e garantida uma concepção de educação, sua inscrição como direito social, bem como os princípios norteadores para a educação brasileira. E ainda, conforme seu art. 214, estabeleceu a formulação do PNE resguardando os princípios constitucionais:

[...] a lei estabelecerá o plano nacional de educação, de duração plurianual, visando à articulação e ao desenvolvimento do ensino, em seus diversos níveis, e à integração das ações do poder público que conduzam à: I erradicação do analfabetismo; II - universalização do atendimento escolar; III - melhoria da qualidade do ensino; IV - formação para o trabalho; V promoção humanística (BRASIL, 1988).

Esse princípio constitucional foi regulamentado pela Lei de Diretrizes e Bases da Educação Nacional (LDB), Lei n 9.394, que estabeleceu em seu art. $9^{\circ}$ inciso I, que cabe a União elaborar o PNE em colaboração com os estados, Distrito Federal e municípios. E no primeiro parágrafo de seu art. 87 determinou que:

[...] a união, no prazo de um ano a partir da publicação desta Lei, encaminhará, ao Congresso Nacional, o Plano Nacional de Educação, com diretrizes e metas para os dez anos seguintes, em sintonia com a Declaração Mundial sobre Educação para Todos (BRASIL, 1996).

De acordo com Saviani (2014), plano educacional é um instrumento de inserção da racionalidade na prática educativa cuja finalidade é a superação do caráter espontaneísta e improvisos que são características contrárias a uma educação sistematizada.

Assim, historicamente a consolidação do PNE tomou caminhos antagônicos no tocante à construção das políticas educacionais. Tal pressuposto foi efetivado com a aprovação do PNE (2001-2011), que apesar de aprovado pelo Congresso Nacional e sancionado pela Presidência da República não representou uma referência de planejamento das políticas para a educação.

No processo de construção e debate o PNE (2001-2011) concorreu com a apresentação de dois projetos: "Plano Nacional de Educação: proposta da sociedade brasileira", apresentado como uma síntese coletivamente construída das aspirações de entidades educacionais (marcada por profissionais da educação, educadores, estudantes) durante o I e II Congresso Nacional de Educação; e outra proposta encaminhada pelo Executivo Federal. As propostas apresentaram concepções e prioridades contrárias no que concerne a “[...] abrangência das políticas, no 
financiamento e gestão, bem como no diagnóstico, prioridades, diretrizes e metas" (DOURADO, 2017, p. 36).

A primeira proposta foi expressa no Projeto de Lei (PL) n. 4.115 encabeçado pelo deputado Ivan Valente, do Partido dos Trabalhadores (PT) de SP, com apoio dos parlamentares e líderes de oposição. Já o projeto do Executivo Federal foi apresentado pelo PL nº 4.173 e anexado à primeira proposta de Plano. Como a grande maioria do congresso estava na base aliada do governo, a proposta do Executivo Federal teve apoio dos congressistas e foi lançada como referência para os debates em torno do novo PNE.

Seguindo os preceitos constitucionais e da LDB, em 9 de janeiro de 2001 foi aprovado o PNE (2001-2011). Esse Plano expressou a lógica das políticas governamentais vigentes com a “[...] adoção de políticas focalizadas, com forte ênfase no ensino fundamental e a efetivação de vários instrumentos e dispositivos, visando à construção de um sistema de avaliação da educação" (DOURADO, 2017, p. 37). Tal proposta se distanciou do conjunto de princípios defendidos pela sociedade brasileira, como a instituição e redefinição do SNE, o Fórum Nacional de Educação, o Conselho Nacional de Educação e a ampliação de 10\% do Produto Interno Bruto (PIB) para o financiamento. Segundo Dourado (2010, p. 684),

[...] o PNE, apesar de apresentar metas de amplo alcance, indicando grandes desafios para a melhoria da educação nacional, configurou-se como plano formal, marcado pela ausência de mecanismos concretos de financiamento. Outro aspecto a ser realçado refere-se à dinâmica global de planejamento adotada, em que não se efetivou a organicidade orçamentária para dar concretude às metas do PNE, na medida em que o Plano não foi levado em conta no processo de elaboração do Plano Plurianual (PPA) e de suas revisões. Esse cenário é revelador de um dos seus grandes limites estruturais.

Além disso, o PNE (2001-2011) apresentou metas e objetivos que expressaram incontroversas, obviedade e ambiguidade nas suas 295 metas distribuídas em onze áreas, o que o caracterizou como uma mera carta de intenções sem possibilidade de materialização das metas.

Tal PNE expôs metas a serem alcançadas pelos diferentes entes federativos, contudo a não regulamentação do regime de colaboração previsto na CF de 1988 representou limites para a efetivação dessas metas. Por isso mesmo, a elaboração dos PEEs e PMEs não se materializou na maior parte dos entes federados brasileiros, o que inviabilizou a constituição do PNE enquanto uma política de Estado (DOURADO, 2010).

A construção de um novo PNE no período de 2010 a 2014 resultou na aprovação do PNE (2014-2024) em de 25 de junho de 2014. Esse Plano, composto por 20 metas e 245 
estratégias, foi emblemático na centralidade das políticas de privatização, revelando disputas por um projeto de sociedade e de educação explicitadas via Conferências Nacionais de Educação (CONAE).

A sua aprovação foi resultado de debates com a participação popular por meio da edição CONAE 2010 "Construindo o Sistema Nacional de Articulado de Educação: o Plano Nacional de Educação: diretrizes e estratégias de ação", precedida de etapas estaduais, municipais e do Distrito Federal. A realização desses encontros resultou no documento base para a elaboração do PL n. 8.035 aprovado pelo Congresso Nacional após três anos e meio de tramitação, sem nenhum veto. Entre os temas discutidos, destaca-se os desafios históricos para a elaboração do SNE que, para Saviani (2010, p. 381), seriam

[...] os obstáculos econômicos decorrentes da histórica resistência à manutenção da educação pública no Brasil; b) os obstáculos políticos caracterizados pela descontinuidade nas políticas educativas; c) os obstáculos filosófico-ideológicos, isto é, a prevalência das ideias ou mentalidades pedagógicas refratárias à organização da educação na de um sistema nacional; d) os obstáculos legais materializados na resistência à incorporação da ideia de sistema nacional na nossa legislação educacional, cuja ponta de lança se ancorava na suposta e logicamente inconsistente tese da inconstitucionalidade da proposta de Sistema Nacional de Educação.

A correlação de força durante a construção do PNE (2014-2024) teve, por um lado, a defesa de propostas educacionais emanadas dos movimentos sociais e, por outro, o empresariamento da educação, “[...] contra as teses da educação pública, gratuita, universal, laica e unitária, [revelando] [...] a disputa ativa pela hegemonia do pensamento educacional mercantil no seio das escolas públicas" (FRIGOTTO, 2011, p. 245). A materialização do referido Plano representa o debate entre o Estado e o mercado na condução da política educacional.

Muito embora, no caso brasileiro, a construção do PNE significou para a política educacional um avanço para as etapas da educação básica e para o ensino superior, essa construção foi assinalada pela ausência de um sistema nacional de educação, por políticas marcadas pela descontinuidade, pela regulamentação da cooperação federativa que garanta os meios de acesso à educação (DOURADO, 2017).

Podemos dizer que a elaboração desse PNE 2014-2024 decorreu de um processo de correlação de forças com diferentes setores para a construção de um projeto de sociedade. $\mathrm{O}$ que significou, no sentido atribuído por Dourado (2017), o epicentro da política educacional mesmo com tensões, apresentando, de um lado, a educação como direito social e, de outro, como uma mercadoria referenciada pelo setor privado. 
E a sua aprovação se deu, após quatros anos de debates, embates, pressões, projetos, emendas e consultas, com o objetivo de orientar as políticas educacionais por dez anos e discutir a instalação do SNE, cabendo agora às unidades subnacionais a elaboração ou a adequação dos seus planos locais de educação. No primeiro ano de vigência, o novo PNE exigiu dos 27 estados e dos 5.570 municípios o alinhamento dos PEEs e PMEs ao texto nacional.

Frente a isso, para que os entes federados elaborassem seus planos, com metas articuladas às metas nacionais, o Ministério da Educação (MEC), em conjunto com o Conselho Nacional de Secretários de Educação (Consed) e com a União Nacional dos Dirigentes Municipais de Educação (Undime), criou uma Rede de Assistência Técnica, que orientou as Comissões Coordenadoras na elaboração dos PEE e PME.

Segundo Saviani, o alinhamento dos planos subnacionais ao PNE intenta a construção de SNE, para a efetivação do regime de colaboração como requer o Estado brasileiro. Na verdade,

[...] trata-se de construir um verdadeiro Sistema Nacional de Educação, isto é, um conjunto unificado que articula todos os aspectos da educação no país inteiro, com normas comuns válidas para todo o território nacional e com procedimentos também comuns visando assegurar educação com o mesmo padrão de qualidade a toda a população do país. Não se trata, portanto, de entender o Sistema Nacional de Educação como um grande guarda-chuva com a mera função de abrigar 27 sistemas estaduais de ensino, incluído o do Distrito Federal, o próprio sistema federal de ensino e, no limite, 5.565 sistemas municipais de ensino, supostamente autônomos entre si (2010, p. 384).

Isto posto, o art. $8^{\circ}$ do PNE (2014-2024) estabelece que os estados, o Distrito Federal e os municípios deverão elaborar, no prazo de um ano, seus planos de educação, ou adequar os Planos já aprovados em lei, em consonância com as diretrizes, metas e estratégias previstas nesse PNE (BRASIL, 2014). Define ainda que os PMEs deverão estar alinhados às metas dos Planos Nacional e Estadual de Educação.

A construção e adequação desses Planos devem levar em consideração as especificadas dos estados e municípios no sentido de consoantes ao PNE também privilegiarem os aspectos ímpares de cada um deles, dentre eles, a questão cultural, étnica, financeira, estrutural e organizacional.

O art. $9^{\circ}$ do PNE (2014-2024) define também que entes federados deverão aprovar leis específicas para os seus sistemas de ensino, disciplinando a gestão democrática da educação pública nos respectivos âmbitos de atuação, no prazo de 2 anos contado da publicação da Lei, adequando, quando for o caso, a legislação local já adotada com essa finalidade. Assim, a gestão 
democrática da educação é condição fundamental para o fortalecimento da autonomia, participação popular e controle social da educação em todos os níveis de ensino.

Dado tal afirmação, na próxima seção abarcamos a gestão educacional e como esta é apresentada nos Planos de educação.

\section{A gestão educacional nos planos de educação}

A gestão educacional é tema muito discutido na produção educacional brasileira, conforme sinalizado pelo levantamento inicial. Segundo Alves (2015, p. 14), ela "tem em vista a organização, mobilização e articulação de todos os recursos materiais e humanos indispensáveis para a promoção efetiva da aprendizagem dos alunos" e, enquanto processo, precisa ser organizada e reorganizada constantemente, conforme os anseios cotidianos do meio educacional, para a promoção de uma educação de qualidade.

Considerando que existem diferentes concepções de gestão educacional, podendo serem adjetivadas ora de democrática, burocrática, compartilhada, participativa, de Qualidade Total, estratégica, gerencial, dentre outros, nesse artigo nos atemos apenas à concepção de gestão democrática da educação, que passou a se constituir em um princípio constitucional a partir da CF de 1988, sendo considerado um ganho normativo importante para a democratização da sociedade e da educação brasileira.

De acordo com Alves (2014), é considerada um processo administrativo políticopedagógico com a participação efetiva direta e representativa da sociedade em todos os âmbitos da educação, com real poder de interferência.

Conforme Freitas (2003), essa gestão tem em vista diálogo, cooperação, descentralização de poder. Ela busca a emancipação e a transformação social de seus envolvidos, bem como a formação de cidadão críticos.

Essa gestão apresenta como principais características educação universal, pública e de qualidade; participação efetiva, direta e indireta da sociedade em todos os níveis de decisão e execução da educação; autonomia didático-científico, administrativa e de gestão financeira e patrimonial; trabalho coletivo, articulado e interativo; respeito à maneira de ser, agir e pensar dos cidadãos; transparência; ambiência favorável à aprendizagem e estimuladora do querer aprender; liberdade de expressão (ALVES, 2014).

A gestão democrática da educação é reafirmada na LDB/1996, em seu art. 14, apresentando como incumbência dos sistemas de ensino disciplinar a gestão democrática em sua jurisdição, tendo como princípios a participação dos profissionais da educação na 
elaboração do projeto pedagógico da escola e a participação das comunidades escolar e local em Conselhos Escolares e equivalentes.

Apresenta ainda em seu art. 15 que os sistemas de ensino devem assegurar às escolas públicas que os integram progressivos graus de autonomia pedagógica, administrativa e de gestão, e no seu art. 12 que os estabelecimentos de ensino devem se articular com as famílias e a comunidade, a fim de edificar processo de integração da sociedade com a escola.

Apesar de ser um ganho essa Lei ter prescrito a participação da comunidade escolar e local nas decisões escolares, ela não regulamenta a gestão democrática da educação de forma mais precisa, deixando para os estados e municípios a tomada de decisão concernente a organização da gestão educacional nos sistemas de ensino, reduzindo a gestão democrática ao âmbito escolar e somente à participação representativa através dos conselhos (ALVES, 2015).

O PNE (2001-2011) reafirma os art. 14 e 15 da LDB/1996, apresentando como um de seus objetivos

a democratização da gestão do ensino público, nos estabelecimentos oficiais, obedecendo aos princípios da participação dos profissionais da educação na elaboração do projeto pedagógico da escola e a participação das comunidades escolar e local em conselhos escolares ou equivalentes (BRASIL, 2001, s/p).

Tem como uma de suas sessões a V - Financiamento e Gestão, que como o nome mesmo supõe trata do financiamento e da gestão da educação e apresenta como principais estratégias: a criação de mecanismos para estimular a participação da comunidade na gestão, tais como conselhos ou equivalentes; o aperfeiçoamento do regime de colaboração entre os sistemas de ensino no que diz respeito ao compartilhamento de responsabilidades; o estímulo à edificação de Conselhos Municipais de Educação e o apoio técnico aos municípios que constituírem seus sistemas municipais de ensino; a definição de normas de gestão democrática do ensino público, com a participação da comunidade, em cada sistema de ensino.

Também são estratégias desse Plano a desburocratização e a flexibilização de normas e diretrizes pelos sistemas de ensino; a descentralização, a autonomia da escola, a equidade, o foco na aprendizagem dos alunos e a participação da comunidade; a garantia da autonomia administrativa e pedagógica das escolas e a ampliação de sua autonomia financeira, através do repasse de recursos diretamente às escolas para pequenas despesas de manutenção e cumprimento de sua proposta pedagógica; o estabelecimento de programas de formação continuada e atualização aos diretores escolares em todos os estados, com a colaboração dos municípios e das universidades; a formação específica em nível superior de diretores, preferencialmente em cursos de especialização e a oferta de cursos de administração escolar 
para tanto; o estabelecimento de políticas e recursos a fim de reduzir as desigualdades regionais e as desigualdades internas a cada sistema. Contudo, nem todas essas estratégias foram materializadas e, como já mencionado, nem todos os municípios e estados brasileiras criaram seus planos de educação.

Já o PNE (2014-2024) apresenta como uma de suas diretrizes a promoção do princípio da gestão democrática da educação pública. Em sua estratégia 2.9 estabelece que os pais ou responsáveis deveriam ser incentivados a participar do acompanhamento das atividades escolares dos filhos através do estreitamento das relações entre as escolas e as famílias. Sua meta 19 trata especificamente da gestão educacional:

[...] assegurar condições, no prazo de 2 (dois) anos, para a efetivação da gestão democrática da educação, associada a critérios técnicos de mérito e desempenho e à consulta pública à comunidade escolar, no âmbito das escolas públicas, prevendo recursos e apoio técnico da União para tanto (BRASIL, 2014).

Diferentemente da normatização que antecedeu esse Plano, que vieram deixando a cargo dos sistemas de ensino a organização e normatização da gestão educacional, com a participação da comunidade, essa meta associa a gestão democrática da educação a critérios técnicos de eficiência, meritocracia e desempenho escolar, não apresentando a gestão democrática da educação associada à formação crítica dos cidadãos, como requer a literatura educacional, e sim à busca pelo desempenho escolar.

Também em sua estratégia 7.4, o PNE (2014-2024) associa a gestão democrática ao planejamento estratégico e as estratégias 7.16 e 7.36 à meritocracia. A estratégia 7.4 aponta que as escolas de educação básica deveriam realizar um processo constante de autoavaliação, a partir do estabelecimento de instrumentos de avaliação que tenham como norte, dentre suas dimensões, o aprimoramento da gestão democrática.

Na estratégia 7.16 abarca que a gestão escolar deveria ter apoio técnico e financeiro por meio de transferência direta de recursos financeiros à escola, a fim de garantir a participação da comunidade escolar no planejamento e na aplicação dos recursos, com vistas a alargar a transparência e o efetivo desenvolvimento da gestão democrática. Já sua estratégia 7.36 firma que deveriam ser estabelecidas políticas de estímulo às escolas na finalidade de melhorar o desempenho no Índice de Desenvolvimento da Educação Básica (Ideb), de modo a valorizar o mérito do corpo docente, da direção e da comunidade escolar.

A meta 19 apresenta oito estratégias. A estratégia 19.1 tem em vista a priorização do repasse de transferências voluntárias da União na área da educação para os entes federados que 
apresentem legislação específica que regulamente a matéria na área de sua abrangência, conforme a legislação nacional, e que considere tanto os critérios técnicos de mérito e desempenho como a participação da comunidade escolar para a nomeação dos diretores escolares. Associa essa participação a um papel de fiscalizador e não de participante ativa das tomadas de decisões e na execução das ações na educação, conforme os anseios da comunidade.

A estratégia 19.2 busca o alargamento dos programas de apoio e de formação aos conselheiros dos conselhos regionais, dos conselhos de alimentação escolar, dos conselhos de acompanhamento e controle social do Fundo de Manutenção e Desenvolvimento da Educação Básica e de Valorização dos Profissionais da Educação (Fundeb) e de outros conselhos. Visa também a ampliação dos programas de apoio e formação aos representantes educacionais e demais conselhos de acompanhamento de políticas públicas. Essa estratégia tem o intuito de assegurar a esses colegiados recursos financeiros, espaço físico adequado, equipamentos e meios de transporte para visitas à rede escolar, no objetivo de obter bom desempenho de suas funções.

A estratégia 19.3 tem como intento o incentivo à construção de Fóruns Permanentes de Educação por parte dos estados, do Distrito Federal e dos municípios, que teriam como incumbência a coordenação das conferências municipais, estaduais e distrital, além da realização do acompanhamento da execução deste PNE e dos PEEs PMEs das localidades onde estes Fóruns estariam inseridos.

A estratégia 19.4 visa incentivar a organização e o fortalecimento de grêmios estudantis e associações de pais em todas as redes de educação básica, a fim de que estas redes garantam aos grêmios estudantis e associações de pais espaços adequados e condições de funcionamento nas escolas, assim como a promoção da articulação orgânica com os conselhos escolares, através das respectivas representações.

A estratégia 19.5 busca impulsionar a implantação e o fortalecimento de conselhos escolares e Conselhos Municipais de Educação, através da implementação de programas de formação de seus conselheiros e da garantia de condições de funcionamento autônomo, para que estes conselhos atuem como instrumentos de participação e fiscalização na gestão escolar e educacional.

A estratégia 19.6 tem como intento estimular a participação e a consulta de profissionais da educação, alunos(as) e seus familiares no que concerne à formulação dos projetos políticopedagógicos, currículos escolares, planos de gestão escolar e regimentos escolares. Busca incentivar, ainda, a garantia da participação dos pais na avaliação de docentes e gestores escolares. 
Podemos dizer que as estratégias 19.2, 19.3, 19.4 e 19.5 tem em vista a ampliação e fortalecimento da participação representativa da comunidade escolar e local e da sociedade em conselhos de educação e no Fórum de Educação. Essas estratégias ampliam a participação em conselhos, já que o PNE (2001-2021) também apresentava como parte de suas metas a participação em conselhos escolares ou equivalentes e no Conselho Municipal de Educação.

Já a meta 19.6 busca garantir a participação direta dos profissionais da educação, pais e alunos nos diferentes aspectos pedagógicos da escola e a avaliação por parte dos pais no que diz respeito ao trabalho realizado pelos professores e diretores na instituição escolar.

A estratégia 19.7 objetiva garantir processos de autonomia pedagógica, administrativa e de gestão financeira nos estabelecimentos de ensino; e a estratégia 19.8 tem em vista o desenvolvimento de programas de formação de diretores e gestores escolares, bem como a aplicação de prova nacional específica, a fim de auxiliar na definição de critérios objetivos para o provimento dos cargos de direção escolar, de modo que os resultados possam ser utilizados por adesão.

Conforme Alves (2015, p. 97), esse Plano

Acrescenta o fortalecimento de processo de autonomia pedagógica, administrativa e de gestão financeira nos estabelecimentos de ensino, bem como a efetivação da gestão educacional democrática por meio de critérios técnicos de mérito e desempenho. Nesse Plano, a gestão educacional democrática apresenta um cunho deliberativo, com ênfase na participação da comunidade escolar e local em conselhos e equivalentes, no controle e fiscalização da educação.

O PNE (2014-2024), apresenta como estratégias a ampliação e fortalecimentos desses Conselhos, que já no momento de elaboração desse Plano estavam sendo ampliados enquanto mecanismos de gestão e canais de comunicação, considerados elo entre a escola e a comunidade - Conselho Escolar, Associação de Pais e Mestres (APM) e Grêmio Estudantil -, assim como entre Estado e a comunidade (conselhos de acompanhamento de políticas públicas e Fórum de Educação).

Contudo, o PNE (2014-2024) ressignifica a concepção de gestão democrática da educação ao apresentar como meta e estratégias para essa gestão critérios de desempenho e meritocracia (ALVES, 2015; OLIVEIRA, 2011), a autoavaliação e a participação dos pais como controladores e fiscalizadores das ações realizadas na escola.

No que concerne aos PMEs e aos PEEs, com base em pesquisa realizada notamos que os municípios têm elaborado ou adequado seus Planos ao PNE (2014-2024) sem realizar muitas alterações, não realizando, assim, adequações conforme suas especificidades, realizando uma 
reescrita do texto desse PNE, inclusive da Meta 19, que trata da gestão educacional, associandoa a critérios de desempenho e à meritocracia, como no PNE (2014-2024). Resta saber se essas metas já estão sendo implementadas no âmbito dos estados e municípios.

\section{Considerações finais}

Tanto o PNE (2001-2021) como o PNE (2014-2024), assim como a normatização educacional que os antecedem, apresentam como concepção de gestão a democrática, com vistas à participação da comunidade escolar nas escolas e em conselhos de educação ou equivalentes.

O PNE (2001-2021) está mais consoante com a concepção de gestão democrática da educação apresentada na literatura educacional, já que apresenta como estratégias a desburocratização; a flexibilização, a descentralização, a autonomia da escola, a equidade, o foco na aprendizagem dos alunos e a participação da comunidade; o estabelecimento de políticas e recursos para a reduzir as desigualdades regionais e as desigualdades internas a cada sistema.

O PNE (2014-2024) amplia os conselhos de educação como mecanismos de gestão democrática, estimulando a criação de novos conselhos e o fortalecimento dos já existentes, com um cunho mais deliberativo. Contudo, ressignifica a concepção de gestão democrática da educação

Os estados e municípios devem elaborar ou adequar seus planos para que esses estejam consoantes ao PNE, sem deixar de privilegiar suas especificidades. Contudo, nem sempre é o que ocorre, já que vêm replicando o PNE, sem apresentar os seus aspectos singulares, o que não expressa alterações consideráveis em relação às suas especificidades, e nem no que se refere à gestão democrática, uma vez que a maioria deles apresenta uma reescrita da meta 19 do PNE (2014-2014). Resta saber se estão colocando-os em prática.

Não podemos deixar de levar em consideração que a construção de ambos os planos passou por debates, embates e pressões, com a defesa de uma proposta advinda dos movimentos sociais e, por outro, com uma proposta educacional mercantilista, apresentada pelo empresariamento da educação, havendo uma disputa pela hegemonia do pensamento educacional. Tais planos correspondem ao debate entre o Estado e o mercado na condução da política educacional, que apresenta uma educação como direito social sem deixar de levar em consideração uma educação mercadológica norteada pelo setor privado, o que implica diretamente na elaboração da concepção de gestão educacional. 


\section{REFERÊNCIAS}

ALVES, A. V. V. Fortalecimento de conselhos escolares: propostas e práticas em municípios sul-mato-grossenses. Dourados-MS: Editora da UFGD, 2014.

ALVES, A. V. V. As formulações para a gestão da educação básica no estado de Mato Grosso do Sul em interseção com as ações da União (1988-2014). Orientadora: Prof. Dra. Maria Dilnéia Espíndola Fernandes. 2015. 285 f. Tese (Doutorado em Educação) Universidade Federal de Mato Grosso do Sul (UFMS), Campo Grande, 2015. Disponível em: https://repositorio.ufms.br:8443/jspui/handle/123456789/2872. Acesso em: 19 fev. 2020.

BRASIL. Constituição (1988). Constituição da República Federativa do Brasil. Brasília, DF, 5 out. 1988.

BRASIL. Lei n. 9.394, de 20 de dezembro de 1996. Estabelece as diretrizes e bases da educação nacional. Diário Oficial da União, Brasília, DF, 23 dez. 1996. Disponível em: http://www.planalto.gov.br/ccivil_03/leis/19394.htm. Acesso em: 19 fev. 2020.

BRASIL. Lei n. 10.172, de 09 de janeiro de 2001. Aprova o Plano Nacional de Educação PNE e dá outras providências. Diário Oficial da União, Brasília, DF, 10 jan. 2001. Seção 1, p. 1. Disponível em: http://www.planalto.gov.br/ccivil_03/leis/leis_2001/110172.htm. Acesso em: 19 fev. 2020.

BRASIL. Lei n. 13.005/2014, de 25 de junho de 2014. Aprova o Plano Nacional de Educação e dá outras providências. Diário Oficial da União, Brasília, DF, 26 jun. 2014. Seção 1, p. 1. Edição Extra. Disponível em: http://www.planalto.gov.br/ccivil_03/_ato20112014/2014/lei/113005.htm. Acesso em: 19 fev. 2020.

DOURADO, L. F. Avaliação do plano nacional de educação 2001-2009: questões estruturais e conjunturais de uma política. Educação e Sociedade, Campinas, v. 31, n. 112, p. 677-705, jul./set. 2010. Disponível em: http://www.scielo.br/pdf/es/v31n112/03. Acesso em: 30 set. 2019.

DOURADO, L. F. O Plano nacional de educação: o epicentro das políticas de Estado para a educação brasileira. Goiânia: Editora da Imprensa Universitária/ANPAE, 2017.

FREITAS, D. N. T de. Sistemas e escolas de educação básica: entre democratizar e compartilhar a gestão. In: SENNA, E. Trabalho, educação e política pública: estudos em educação. Campo Grande: UFMS, 2003, p. 189-219.

FRIGOTTO, G. Os circuitos da história e o balanço da educação no Brasil na primeira década do século XXI. Revista Brasileira de Educação, Rio de Janeiro, v. 16, n. 46, p. 235-274, jan./abr. 2011.

LÜCK, H. Concepções e processos democráticos de gestão educacional. Petrópolis: Editora Vozes, 2006. 
SAVIANI, D. Sistema nacional de educação articulado ao plano nacional de educação. Rev. Bras. Educ., Rio de Janeiro, v. 15, n. 44, p. 380- 392, ago. 2010. Disponível em: http://www.scielo.br/pdf/rbedu/v15n44/v15n44a13.pdf. Acesso em: 19 out. 2019.

SAVIANI, D. Sistema nacional de educação e plano nacional de educação: significado, controvérsias e perspectivas. Campinas, SP: Autores Associados, 2014.

OLIVEIRA, D. A. Das políticas de governo a política de Estado: reflexões sobre a atual agenda educacional brasileira. Educação e Sociedade, Campinas, v. 32, n. 115, p. 323- 337, abr./jun. 2011.

\section{Como referenciar este artigo}

ALVES, Andréia Vicência Vitor; ALVES, Andrêssa Gomes de Rezende; VIEGAS, Elis Regina dos Santos. A Gestão Educacional nos Planos de Educação: do nacional ao municipal. Revista Ibero-Americana de Estudos em Educação, Araraquara, v. 15, n. esp. 1, p. 719-734, maio 2020. e-ISSN: 1982-5587. DOI: https://doi.org/10.21723/riaee.v15iesp.1.13345

Submetido em: 30/10/2019

Revisões requeridas: 10/11/2019

Aprovado em: 20/12/2019

Publicado em: 30/04/2020 